(OPEN ACCESS

\title{
Diet-induced oxalate nephropathy
}

\author{
Barbara Clark, ${ }^{\oplus 1}$ Mohammad Wisam Baqdunes, ${ }^{1}$ Gregory M Kunkel ${ }^{2}$
}

${ }^{1}$ Medicine, Allegheny Health Network, Pittsburgh, Pennsylvania, USA

${ }^{2}$ School of Medicine, Drexel University, Philadelphia, Pennsylvania, USA

Correspondence to Dr Barbara Clark, barbara.clark@ahn.org

Accepted 22 August 2019

Check for updates

(c) BMJ Publishing Group Limited 2019. Re-use permitted under CC BY-NC. No commercial re-use. See rights and permissions. Published by BMJ.

\footnotetext{
To cite: Clark B,

Baqdunes MW,

Kunkel GM. BMJ Case

Rep 2019;12:e231284.

doi:10.1136/bcr-2019-

231284
}

\begin{abstract}
SUMMARY
Oxalate nephropathy is a rare condition and may be overlooked due to lack of recognition and understanding of triggers. An 81-year-old man was sent to nephrologist because of significantly increased creatinine (1.5-1.9 mg/dL) noted for 3 months. He had well-controlled diabetes but no history of kidney disease. He had no chronic diarrhoea or intestinal surgery. He was a health-minded individual who had read extensively about benefit of antioxidants. Initial work-up was unrevealing. Within a few weeks after first visit, he developed acute symptomatic worsening kidney injury with nausea, vomiting and creatinine up to $6.8 \mathrm{mg} / \mathrm{dL}$. Repeat examination of the urine sediment revealed casts containing calcium oxalate crystals. A deeper dietary history revealed widespread oxalate precursor consumption. A kidney biopsy confirmed oxalate nephropathy. Restriction of oxalate consumption combined with adequate hydration, oral calcium acetate resulted in partial renal recovery without need for haemodialysis.
\end{abstract}

\section{BACKGROUND}

In today's culture of health-conscious living and a focus on organic, whole foods and natural supplements, it is important to note the increasing possibility of medical conditions specifically related to the consumption of extremely high levels of certain nutrients and evaluate accordingly. Oxalate nephropathy may be a rare complication with a long list of precipitating factors, but should be on the differential in the absence of findings of other, more common renal diseases.

\section{CASE PRESENTATION}

An 81-year-old man with history of 30 years of diabetes mellitus type 2 (DM) was referred to nephrology clinic in summer of 2017 because of recently discovered elevated creatinine $(1.5-1.7 \mathrm{mg} /$ $\mathrm{dL}$ ). His DM was controlled initially with diet and then recent addition of glipizide (heamoglobin A1c (HbA1c) 6.1). Patient did not have any history of diabetic retinopathy or nephropathy and baseline creatinine was normal at $0.8 \mathrm{mg} / \mathrm{dL}$ in 2016 with no significant albuminuria. He denied any urinary symptoms, haematuria, flank pain or history of kidney stones. He had no weight loss, malaise, fever or other constitutional symptoms. He denied nonsteroidal anti-inflammatory drugs (NSAIDs). $\mathrm{He}$ was taking only multivitamins, vitamin C $500 \mathrm{mg}$ PO daily and glipizide. He had no family history of kidney disease or kidney stones. He did not smoke, rarely drank alcohol and had never consumed ethylene glycol. There were no reports on hypotension. He had no malabsorptive symptoms or history of gastric bypass. At presentation, vital signs were within normal range and physical exam was unremarkable.

\section{INVESTIGATIONS}

Initial urinalysis showed no protein, red cells or white cells. Twenty-fourhours urine protein was $258 \mathrm{mg}$, and urine protein and serum protein electrophoresis were normal, but he did have anaemia and a low level light chain monoclonal gammopathy (IgM kappa) of uncertain significance, so he was referred to haematology.

His renal ultrasound showed normal size kidneys without obstruction or stones. He had a somewhat enlarged prostate and was felt to possibly have a component of obstructive uropathy, so he was referred to urology. However, cause of the kidney injury remained uncertain.

A few weeks later, with no interim change in medications and no nephrotoxin exposure or episodes of hypotension, he developed several days of nausea, vomiting, anorexia and lethargy, and was admitted to the hospital. His labs now showed creatinine of $6.3 \mathrm{mg} / \mathrm{dL}$ (compared with 1.9 , a few weeks earlier and 0.7, 6 months earlier), blood urea nitrogen (BUN) $120 \mathrm{mg} / \mathrm{dL}$, haemoglobin $73 \mathrm{~g} / \mathrm{L}$ and platelets (PLT) $83 \times 10^{9} / \mathrm{L}$. His vital signs were within normal ranges and physical exam was unremarkable.

Because of the concern for an obstructive process due to his enlarged prostate, urology was consulted. They determined that this was not causing his acute renal dysfunction and repeat imaging did not reveal any obstruction. Insertion of Foley catheter produced only $150 \mathrm{cc}$ of urine.

\section{DIFFERENTIAL DIAGNOSIS}

Renal work-up suggested an intrinsic renal disease (urine $\mathrm{Na} 30$ ). Repeat examination of urine sediment had revealed coarse granular casts consistent with acute tubular necrosis (ATN). The reason for ATN, however, was unclear as he had not been exposed to any contrast and there was no observed hypotension. His creatinine improved to $5.3 \mathrm{mg} / \mathrm{dL}$ after giving intravenous fluids for possible component of volume depletion associated ATN from recent vomiting and poor oral intake.

Extensive renal and haematological work-up included mildly suppressed C3 at $81 \mathrm{mg} / \mathrm{dL}$ (normal range $85-194 \mathrm{mg} / \mathrm{dL}$ ), but normal $\mathrm{C} 4$ and negative antineutrophilic cytoplasmic antibody (ANCA) panel, anti-glomerular basement membrane (anti-GBM), dsDNA, normal lactate dehydrogenase 


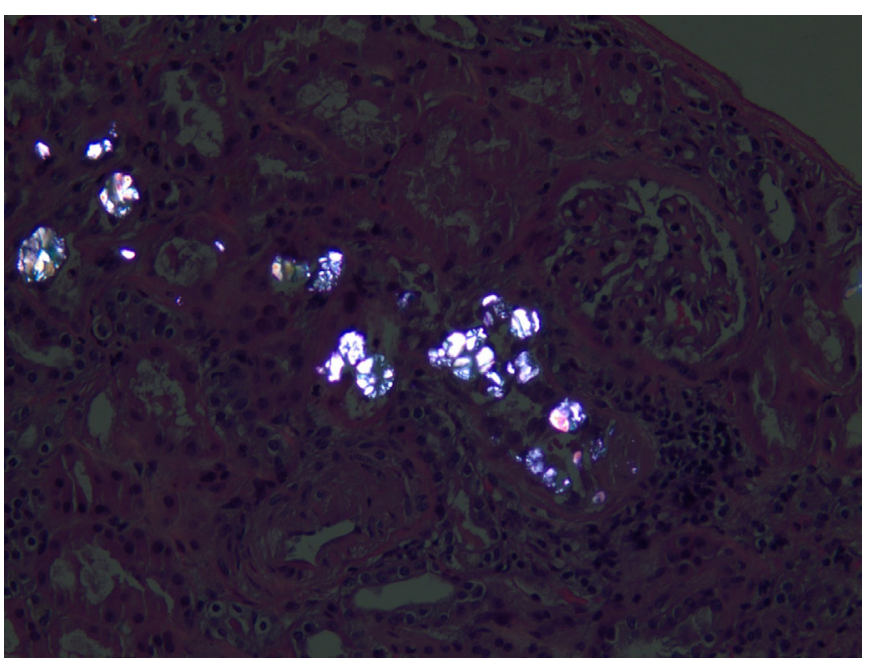

Figure 1 Renal histology with calcium oxalate crystals under light microscopy $(\mathrm{H} \& \mathrm{E}, \times 400)$.

(LDH), haptoglobin, B12, folate and iron studies. Heavy metals including copper, lead, mercury, arsenic and cadmium were within normal limits. Because of the monoclonal gammopathy discovered previously, haematology was consulted. Kappa light chain in serum was $7.03 \mathrm{mg} / \mathrm{dL}$ (normal range $0.3-1.94 \mathrm{mg} / \mathrm{dL}$ ) and lambda was $1.92 \mathrm{mg} / \mathrm{dL}$ (normal range 0.6-2.6). A bone marrow biopsy was performed that was unremarkable.

Uric acid was 5.9. HIV, hepatitis panel and parvovirus studies were all negative. Prostate specific antigen (PSA) was 4.9. Haematologist attributed his anaemia and thrombocytopaenia to the acute changes in kidney function.

Given negative work-up a repeat examination of urine sediment was performed revealing coarse granular casts as well as now noted calcium oxalate crystal casts. Kidney biopsy was also ordered.

The finding on repeat urine examination of oxalate casts triggered a deeper dietary history. He was very health conscious and had read extensively about diet and nutritional supplements noted to be helpful for cancer prevention and diabetes treatment. He had regularly been consuming a litre or more daily of almond milk in addition to wheat germ and many other nuts during the day. He became increasingly concerned after his first

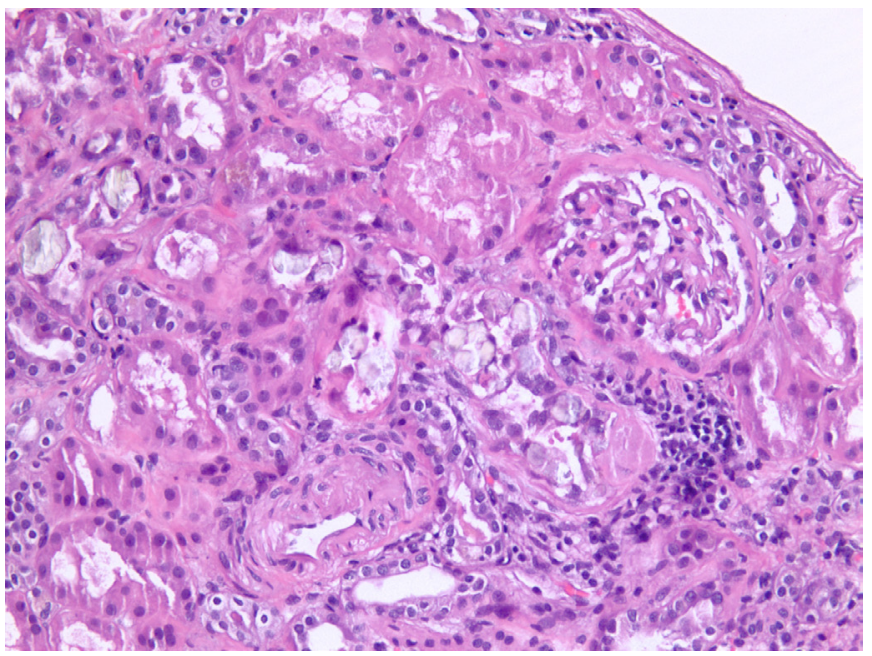

Figure 2 Renal histology with calcium oxalate crystals under light microscopy with polarisation $(\times 400)$. visit to nephrology clinic about prostate health and decided to further increase intake of all these antioxidants. He had increased intake of foods felt to be high in lycopene and antioxidants. This included 2-3 tablespoons of tomato paste per day, hand full of Brazil nuts, hazelnuts, walnuts, pistachios, pecans, almonds, several teaspoons of cocoa powder and wheat germ in addition to the $500 \mathrm{mg}$ of vitamin C PO daily. He continued to drink at least a litre of almond milk daily. He was unaware of the potential of excess oxalate in these foods.

The patient had a kidney biopsy that showed (figures 1 and 2):

1. Tubular oxalosis.

2. Acute tubular injury.

3. Mild glomerular changes consistent with diabetic and hypertensive nephropathy.

4. Mild Interstitial fibrosis and tubular atrophy.

5. Mild to moderate atherosclerosis.

6. Immunofluorescence negative for specific immunoreactants.

7. Congo red stain negative for amyloid.

8. Electron microscopy negative for amyloid and immune deposits.

\section{TREATMENT}

He was diagnosed with acute kidney injury (AKI) and ATN due to oxalate nephropathy secondary to oxalate rich diet especially given the lack of other explanations for his sudden rise in creatinine. He was advised to follow a low oxalate diet, drink plenty of fluids, stop vitamin $\mathrm{C}$ and take calcium acetate to bind oxalate in the intestines. Other experimental treatments considered use of probiotic, Oxalobacter formigenes, that might digest intestinal oxalate but this was not available and was never started.

\section{OUTCOME AND FOLLOW-UP}

Follow-up creatinine levels slowly trended downwards but did not reached his previous baseline levels of around $0.8 \mathrm{mg} / \mathrm{dL}$. On 20 November 2017, his creatinine level was $4.07 \mathrm{mg} / \mathrm{dL}$. By early 2018, his level had reduced to 3.17 and later in September 2018, it was 2.99. Since that time, creatinine has been $2.5-3.3 \mathrm{mg} /$ $\mathrm{dL}$. His BUN has been in the $50-70 \mathrm{mg} / \mathrm{dL}$ range with no signs of uraemia (poor appetite, nausea, metallic taste in mouth and cardiac rub). Electrolytes are within normal limits. Patient started taking low-dose long acting insulin to control blood sugars and HbA1c levels have been around 6. Repeat urinalysis was unremarkable with no casts or crystals. And 24 hours oxalate done several months after his original presentation was found to be within normal limits. The patient is on erythropoietin 1-2 times monthly, and haemoglobin levels have been around 10. He has an active, healthy lifestyle walking several miles per day. He has not resumed vitamin $\mathrm{C}$ or high oxalate foods or supplements, continues to take calcium oxalate with meals and continues to drink at least $2 \mathrm{~L}$ of water daily.

\section{DISCUSSION}

While there is increasing recognition of oxalate nephropathy as a cause of otherwise difficult to explain acute renal failure or ATN the diagnosis can still remain elusive due to missing or unsolicited details of medical history. ${ }^{1}$ Oxalate nephropathy can be primary or secondary. The primary form consists of autosomal recessive inherited enzymatic deficiencies that lead to the increased urinary excretion of oxalate. This can be due to reduction of alanine: glyoxylate aminotransferase activity in the liver (type 1$)^{2}$ or a mutation of glyoxylate reductase/D-glycerate dehydrogenase (type 2$){ }^{3}$ In contrast, secondary hyperoxaluria can be related to increased dietary oxalate intake 
Patient's perspective

I am writing on behalf of my father. First, let me say that we are eternally grateful to our doctor for her determination and expertise in investigating and diagnosing the reasons for my dad's sudden kidney failure, and more so, for her careful follow-up of his care from the point of diagnosis such that he has been able to regain kidney function, avoid dialysis and resume much of his daily routine prekidney failure. We joke that she was a real life 'Columbo'.

To put his case in perspective, prior to falling ill, my dad was the picture of health. Just several weeks prior to his kidney failure, he was clearing heavy brush from his property and cleaning up a small landslide of mud that had run into his neighbour's property. He was not what most think of for an 81-year-old man. Up to the point of his kidney failure, although closely managing type 2 diabetes for approximately 30 years, he had never been hospitalised, never had an intravenous insertion and never been subjected to tests such as CT scans and biopsies.

While we were investigating decline of his kidney function, to which he had no symptoms with the exception of some mild fluid retention in his legs, he became suddenly and visibly ill-his movements slowed and he seemed hardly able to walk; he rapidly lost weight, with not much to lose given his healthy frame, and he considered even water to 'taste like poison', a huge statement for a man that would eat nearly any combination of food if you told him there were health benefits. He needed emergency attention!

Through the admission process, I was so concerned that he would be stereotyped as 'elderly', as simply declining and little would be done to restore his health. My fears worsened by the fact the my dad is a terrible patient-terrible at giving solid answers to questions, terrible at paying attention to instructions and terrified about the new environment in which he found himself. I told every nurse, assistant and doctor that walked into his room, and there were many, of what my dad was like before this sudden illness. I needed him to be more than just another elderly person with diabetes that led to kidney failure. I knew this wasn't his case. The kidney specialist listened and was persistent and amazing!

For as long as I can remember, my dad looked to his diet (and supplements), to fix anything that ailed him. With each new doctor that walked into the room, regardless of their specialty, he began to tell him about his diet. I became frustrated. At the time, doctors were speculating that he had some type of blood cancer. I remember even yelling at him, 'Dad-they think you have blood cancer; diet isn't going to fix this.' As it turns out, diet was both cause and the cure, indicating that one can have too much of a good thing. To his dismay, he has had to totally change his diet (I know he misses his nuts), but he has largely recovered. His kidney failure and hospitalisation, however, took a significant toll on him. My mother, who is also in excellent health, and I both said that he became an old man overnight. That sentiment didn't completely rectify with his recovery. He lost his youthfulness; he is slower moving and less nimble and he seems to have had some type of post traumatic stress disorder (PTSD), blocking out all medical knowledge, including 30 years of expertise in managing his diabetes. Also the deficits to his kidneys have come with other problems he has never had to face including anaemia and high blood pressure. Nevertheless, he survived and remains physically active, walking miles every day!

Continued

\section{Patient's perspective Continued}

We are so glad this case study is being written, as it highlights many important things, even beyond pure medical knowledge. It highlights the potential dangers of supplementation when one doesn't have a full understanding of the impact on the entire system; and highlighted the importance of diet in assessing someone's health, including a diet that is too exclusive or laden with a harmful substance (in this case, oxalates, which is a term that the average person will know nothing about). My experience with doctors is that diet is not often discussed or discussed at such a high level that my dad's diet would have simply been praised. I understand that, with the right knowledge and cautions, his kidney issues would have been completely preventable. It wouldn't have helped that he rarely went to the doctor, but for someone who does go, such cautions could be life saving. The other thing that it highlights says that unusual symptoms should be explored at the onset. A year so before blood work revealed any deficit in my dad's kidney function, he began to retain fluid in his legs. I know this might have been even more like finding in needle in a haystack, but it was a chance to course correct that we all collectively missed. We are grateful for the opportunity to share my dad's story and his recovery, and we hope this case provides additional information and perspective that can help many more people like him, in the future.

or oxalate precursors, or enteric hyperoxaluria where there is increased absorption of oxalate from the bowel. This is usually related to fat malabsorption, which leads to increased absorption of oxalate from the colon. Typically, calcium would bind to oxalate in the gut but instead binds to free fatty acids that cannot be absorbed, hence less calcium to bind to oxalate in the stool and leads to increase availability of absorbable soluble oxalate in the colon. This can occur with use of orlistat therapy, ${ }^{4}$ Roux-en-Y gastric bypass surgery, ${ }^{6}$ coeliac disease and Crohn's disease (when colon is still intact). Excess oxalate by oral means can occur with ingestion of oxalate precursors, such as with ethylene glycol ingestion, and has also been reported with excess ingestion of ascorbic acid. ${ }^{17}$

Increased dietary intake of oxalate leading to acute kidney injury is fairly uncommon; however, there have been case reports in the literature describing excessive consumption of cashew nuts, vitamin $\mathrm{C}$ supplementation, spinach and peanuts. ${ }^{18-11}$ Our case report differs from those previously cited in that no single dietary agent was implicated but rather a 'health conscious, antioxidant' diet was identified as the inciting factor in the development of the oxalate nephropathy. In our described case, the patient consumed many different foods with high oxalate levels, although all in moderation of 1-2 servings per day. Even by practising the belief of 'everything in moderation', our patient still consumed nearly $1500 \mathrm{mg}$ of oxalate daily, up to $10 \times$ greater than the average American. The initial presentation of these cases differed from one another. One presented with pneumonia, was transferred to the ICU and vitamin $\mathrm{C}$ supplementation there caused the nephropathy. ${ }^{9}$ Cases can present with nausea, vomiting, weakness and altered mental status (as in our case). Several cases have initially presented with decreased kidney function. The diagnosis in all cases was determined by kidney biopsy showing tubular oxalate crystals. However, our case highlights the importance of careful and sometimes repeat examination of the urine sediment in confusing cases. The repeat 
urine sediment was the first hint of the pathology. Other cases in the literature have noted various degrees of complete recovery, partial recovery and end-stage renal disease dependent on haemodialysis. Some required haemodialysis during the recovery phase. Risk factors that our patient had for worsening kidney function were advanced age and previous diagnosis of diabetes. He did not have any bowel conditions, known genetic conditions or family history of kidney disease. Therefore, it is reasonable to understand why our patient had partial recovery of kidney function. In the case attributed to spinach intake, the patient also had advanced age and previous diagnosis of diabetes, but also had a history of Roux-en-Y gastric bypass procedure with the outcome of end stage renal disease (ESRD) on haemodialysis (HD). One case related to vitamin C supplementation did not discuss pre-presentation kidney function, but 6-month follow-up glomerular filtration rate (GFR) showed stage 4 chronic kidney disease (CKD). Another case with vitamin $\mathrm{C}$ ingestion required dialysis (presenting creatinine $10.6 \mathrm{mg} / \mathrm{dL}$, follow-up creatinine $1.9 \mathrm{mg} / \mathrm{dL}$ at 5 weeks postdischarge, baseline of $1.3 \mathrm{mg} / \mathrm{dL}){ }^{1}$ The only case to show near total recovery was related to peanut consumption showed creatinine clearance near baseline $(1.0 \mathrm{mg} /$ dL compared with $0.82 \mathrm{mg} / \mathrm{dL}$ ) and a GFR $>90$ after recovery. Another case to show partial recovery was related to cashew nut ingestion (creatinine of $1.4 \mathrm{mg} / \mathrm{dL} 8$ months after recovery compared with $0.80 \mathrm{mg} / \mathrm{dL}$ baseline).

\section{Learning points}

- A thorough and extensive history that includes dietary history should be taken in all patients with unexplained kidney disease, as patients may unknowingly cause disease by trying to prevent others, particularly as high oxalate foods, such as nuts and spinach and foods high in vitamin $\mathrm{C}$ are considered healthy.

- The urine sediment examination can provide critical insight into diagnosis and repeat examinations may be needed.

- Kidney biopsy is the confirmatory test for diagnosis of oxalate nephropathy.

Even when acute kidney injury is severe, renal recovery can occur but may be slow.
Because of the rarity of diet-induced oxalate nephropathy, specific treatment guidelines do not exist. However, the management of enteric hyperoxaluria has been described. The recommended management is low oxalate diet, high fluid intake, calcium carbonate (to bind oxalate) and potassium citrate (to correct metabolic acidosis). ${ }^{12}$ We prescribed low oxalate diet, high fluid intake and calcium acetate (to achieve both binding of oxalate and control of phosphate).

Contributors BC, MWB and GMK participated in the clinical care or diagnostic testing, assembling of data, contributed to the intellectual content of the case report, writing of the case report, and actively reviewed and edited the content.

Funding The authors have not declared a specific grant for this research from any funding agency in the public, commercial or not-for-profit sectors.

Competing interests None declared.

Patient consent for publication Obtained.

Provenance and peer review Not commissioned; externally peer reviewed.

Open access This is an open access article distributed in accordance with the Creative Commons Attribution Non Commercial (CC BY-NC 4.0) license, which permits others to distribute, remix, adapt, build upon this work non-commercially, and license their derivative works on different terms, provided the original work is properly cited and the use is non-commercial. See: http://creativecommons.org/ licenses/by-nc/4.0/

\section{REFERENCES}

1 Lamarche J, Nair R, Peguero A, et al. Vitamin C-induced oxalate nephropathy. Int Nephrol 2011;2011:1-4.

2 Watts RW. Primary hyperoxaluria type I. QJM 1994:87:593-600.

3 Seargeant LE, deGroot GW, Dilling LA, et al. Primary oxaluria type 2 (L-glyceric aciduria): a rare cause of nephrolithiasis in children.J Pediatr 1991:118:912-4

4 Karamadoukis L, Shivashankar GH, Ludeman L, et al. An unusual complication of treatment with orlistat. Clin Nephrol 2009:71:430-2.

5 Singh A, Sarkar SR, Gaber LW, et al. Acute oxalate nephropathy associated with orlistat, a gastrointestinal lipase inhibitor. Am J Kidney Dis 2007:49:153-7.

6 Nelson WK, Houghton SG, Milliner DS, et al. Enteric hyperoxaluria, nephrolithiasis, and oxalate nephropathy: potentially serious and unappreciated complications of Rouxen-Y gastric bypass. Surg Obes Relat Dis 2005;1:481-5.

7 Alkhunaizi AM, Chan L. Secondary oxalosis: a cause of delayed recovery of renal function in the setting of acute renal failure. J Am Soc Nephrol 1996:7:2320-6.

8 Bernardino M, Parmar MS. Oxalate nephropathy from cashew nut intake. Can Med Assoc J 2017;189:E405-8.

9 Colliou E, Mari A, Delas A, et al. Oxalate nephropathy following vitamin C intake within intensive care unit. Clin Nephrol 2017;88:354-8

10 Makkapati S, D'Agati VD, Balsam L. "Green Smoothie Cleanse" causing acute oxalate nephropathy. Am J Kidney Dis 2018;71:281-6.

11 Park H, Eom M, Won Yang J, et al. Peanut-induced acute oxalate nephropathy with acute kidney injury. Kidney Res Clin Pract 2014;33:109-11.

12 Nightingale JMD. Hepatobiliary, renal and bone complications of intestinal failure. Best Pract Res Clin Gastroenterol 2003;17:907-29.

Copyright 2019 BMJ Publishing Group. All rights reserved. For permission to reuse any of this content visit

https://www.bmj.com/company/products-services/rights-and-licensing/permissions/

BMJ Case Report Fellows may re-use this article for personal use and teaching without any further permission.

Become a Fellow of BMJ Case Reports today and you can:

- Submit as many cases as you like

- Enjoy fast sympathetic peer review and rapid publication of accepted articles

- Access all the published articles

- Re-use any of the published material for personal use and teaching without further permission

Customer Service

If you have any further queries about your subscription, please contact our customer services team on +44 (0) 2071111105 or via email at support@bmj.com.

Visit casereports.bmj.com for more articles like this and to become a Fellow 